on that method for more than six months trying to get some results, with entirely negative results and I used the most careful methods. It shows how difficult it is to get at these things.

\section{PERIODS OF STRESS AND THEIR DENTAL MARKS.*}

JAMES G. KIERNAN, M.D.

Fellow of the Chicago Academy of Medicine; Foreign Associate Member French Medico-Psychological Association.

\author{
CFICAGO.
}

Despite embryologic teachings, that old notion that man is an entity who undergoes development alone, still controls pathology and physiology. The human being, however, is a compound animal in whom organs have their own nervous system and their own life under control of the cerebrospinal system. The child is not an undeveloped man, but man is an imperfectly developed child. The embryo has to contend with retrogressive as well as progressive factors, and the same is true of man after birth. Vertebrate embryos are of common type at their origin and assume successively many common forms before definitely differentiating. The higher vertebrates contain in essence the organs and possibilities of all lower vertebrates. The human organism is therefore a balance. While the balance is maintained the organs work in unity, though there is a constant struggle for existence between them. During embryonic existence this struggle is more intense and diversified than after maturity, because of the influence of three contending forces: remote atavism or throw-back to primitive types, immediate atavism or throw-back to less remote ancestors of the same type, and finally immediate heredity. Remote atavism tends to preserve structures which occur in the normal embryo only to disappear. The human heart passes through all vertebrate heart phases. This is likewise true of the teeth During the life of the embryo the tooth system waver: at one time between the polyphyodont and the diphyodont. At this period, should the diphyodont tendency of man be arrested. the polyphyodont takes its place and the human being sheds teeth as do reptiles. On the other hand, should immediate atavism gain the ascendancy over remote atavism shown in polyphyodontia, diphyodontia occurs. When the struggle for existence between the two is keenest a period of stress results, which affects the organism as a whole. This stress expresses itself most strongly in dental and maxillary irregularities, since the jaws and teeth are among the most variable structures in evolution. Under what is known as the law of economy of growth is governed the relation of the organs to each other, and the process whereby one structure is sacrificed for the development of another or for the development of the organism as a whole. Since certain parts in the evolution of organs disappear and in the evolution of organisms certain organs through suppressive economy and since the disappearing and developing tendency of necessity centers around the time when certain functions are to be lost by the disappearing and others gained by the developing, periods of stress occur around which the law of economy of growth centers the struggle for existence between parts of organs and between organs themselves. It is because of this that physiologic atrophies and hypertrophies and their reverse occur. Nearly all conditions of physiologic disturbance may result at these periods

* Read in tho Section on Stomatolegy, at the Fifty-second Annual Meeting of the American Medical Association, held at St. Pait. Mimn. June $4-7$. I:Hit. of stress under the influence of maternal environment or of hereditary factors. The fetus, therefore; musi be prepared to pass through not only intra-uterine periods of stress, whose dental mark has already been indicated, but post-uterine periods as well.

The child has not attained its full development at the time of birth. It has within it certain potentialities, some of which are never fully realized. There is a constant struggle between the central nervous system and certain bodily functions for preservation of the individual and for preservation of the race, through which the central nervous system fails to reach the height indicated in the child. This struggle for existence after birth is keenest at certain periods. Each period is marked by dental phenomena. The first is the period of the first dentition. Here, coincident with teething, the child is gaining its impressions of the outside world, is learning to walk and talk, and is also developing its eliminative organs, especially the rectum. These varied functions constitute a strain on the system, effects of which are most often evinced through the teeth and jaws. The conditions charged to teething are an expression of constitutional strain finding its outlet through the point of least resistance. During this first dentition, the strain of development forces attention to the teeth. and thereby leads to neglect of other factors. The teeth at this period should be regarded as a meter of constitutional strain, and not a cause of it. Within the next period, between 2 and 6 , occurs the first great check to continued development of the brain. Man has learned to use his brain despite this check, but had it not occurred he would have had a higher type of brain to use. Sometimes during this period the brain gains in size, albeit not in balance, at the expense of the general system. In no small degree the struggle for existence during this period of stress centers around the development and eruption of the 6th year molar. With the eruption of this molar, premature puberty, sexual precocity, epilepsy, insanity, gout, rheumatism, obesity. and other nutritive degeneracies, may occur. All have been charged to the eruption of the 6th year molar, whereas its irregular or difficult eruption is, like them, an expression of constitutional stress. Hygiene of the teeth at this period means also constitutional, mental and moral hygiene. Epilepsy, for example, is not a disease, but a symptom of weakness of certain vasomotor inhibitions. The first convulsion does not constitute epilepsy. Through a law of the nervous system, nerve action once roused tends to repeat itself. In this way are established normal and abnormal habits, of which last epilepsy is one. In its early stages a habit normal or abnormal is easily checked. The first convulsion, therefore, could be prevented were its premonitions known. A recurrence could also be prevented were the constitutional origin recognized. Observation of the general constitution at this time, because of irregular eruption of the 6th year molar, would enable the physician to nip epilepsy, and many other allied conditions, in the bud. Reflex notions. however, must be flung overboard. All irritations should be removed and any constitutional irregularity treated.

The obese child of 6 years, even though the obesity be not excessive. should be looked upon from a health standpoint with suspicion. There is liability to disease, and marked tendency to systemic weakness when under morbid influence. These children are particularly liable to rheumatism, gout, etc., and profuse hemorrhage from slight eauses. Touthful obesity is sometimes associated 
with precocious maturity and resultant early senescence. More often it co-exists with extended infantilism, as in the case of Dickens' "fat boy."

E. S. Talbot, examining 267 corpulent school children and adolescents, found marked stigmata of degeneracy. Ninety-two per cent. had deformed ears to a marked degree. Sixty-six per cent. had arrested development, as compared with their age, while 12 per cent. presented excessive development. Thirty-four were too young to determine the form and size of the jaw. In 33.5 per cent. of the thirty-four the molars, incisors, cuspids and bicuspids were present. Ninety-six per cent. of these had small teeth. Eighty-seven per cent. (of the 233) had arrested development of the upper jaw; 22 per cent. arrest of lower jaw. Sixty-four per cent. had $V$-shaped or saddle-shaped arches, or their modification, and protruding teeth. Seventeen per cent. had hypertrophy of the alveolar process. Eighty-three per cent. had small teeth. Twenty-seven per cent. had extra tubercles upon the molars. Eighty-two per cent. had stenosis of the nasal cavity more or less marked. Thirtysix per cent. had deflection of the nasal septum to the left and 29 per cent. to the right. Twenty-one per cent. wore glasses for eye defect. In 58 per cent. there was enlargement of the thyroid gland, and in 7 per cent. arrest of development of it. In 296 cases of early lipomatosis (180 male and 116 females) coming under $\mathrm{my}$ own observation, there were 10 cryptorchids, 6 hypospadiacs and 3 cases of pseudo-hermaphroditism. Three females had infantile bifid uteri. Four had enlarged clitorides; in one of these the urethra perforated the clitoris, as in the female shrew. Of 40 girls who had reached 18 , only 3 had menstruated normally. The others were amenorrheic or dysmenorrheic, or had neurotic storms during the period. There were 160 hebephreniacs among the number. Of these 120 had masturbated excessively. Ten had been nymphomaniac or satyriasic, the sexual appetite having become completely extinct at 18. Fifty of the non-hebephreniacs never showed any signs of sexual appetite. Three of the hebephreniacs were sexual inverts, while 80 practiced various perversities. Of the non-hebephreniacs 10 were cyclothymiacs, 30 had acute forms of insanity, 10 were epileptic and 15 hysteric. Thirteen had had chorea. Ninety-seven had difficulty in learning to speak and 30 always stuttered.

The appearance of the first permanent molar is therefore of great significance to stomatologist and sociologist alike. The mental and moral deficiencies usually present will interfere with proper care of the teeth particularly indicated in cases where such deficiencies occur. While the eye has received much attention as a sociologic guide the teeth and jaws have, as a rule, been much neglected, although of even more significance than the functional disorders of the eye.

The next important period of stress is practically that of the second dentition. Here there is a foreshadowing of the mental and nervous phenomena of the following period of stress. Sexual development now frequently receives its initiative. What is true of neuropathic children earlier is true at this time of ordinary children. under conditions of stress. There is irregularity of disturbed sleep, irritability, apprehension, strange ideas, great sensitiveness to external impressions, high temperature, delirium, convulsions from slight causes, disagreeably anxious dreams, romancing, intense fceling, periodic headache, muscular twitching, capricious appetite and marked intolerance of stimulants and

narcotics. The struggle for existence between the developing alimentary and other systems between the $2 d$ and 6th year had produced effects which are most felt during the 6 th to 12 th year. Provided this struggle is between normal limits, the average child does not incur permanent danger from it. If, however, from heredity, congenital defect or improper environment, development of the system does not proceed equably, then strain results, which produces, during this period, not only the conditions already described, but the following as well:

NEURoses.

Convulsions.

Nervous laughs

Nervous coughs

Hiccoughs

Renal

Hepatic

Gastric

Vesical

Genital

Pulmonary

Cardiac

Netabolice

Stuttering

"lic:;"

Neuralgias

Neurasthenia

Eestasy

Hysteria

Chore:

Epilepsy

Somnambulism
Adenopathie

PSYCHIC TYPES.

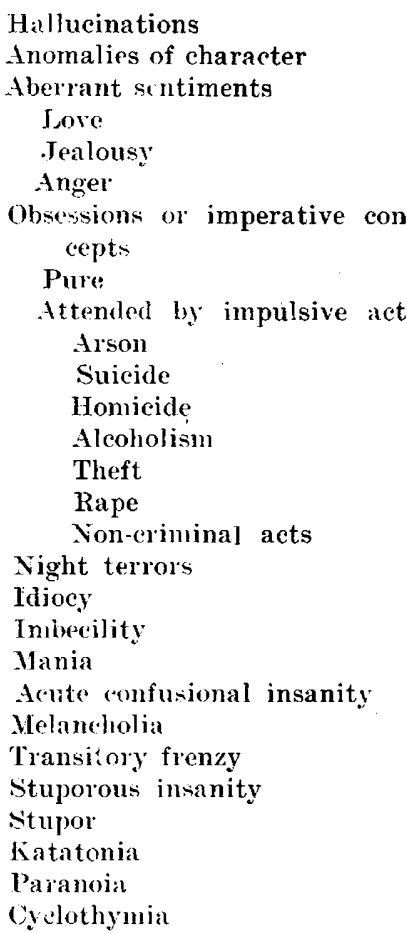

These are apt to occur at this time as a reaction to temporary disturbances of health. The temperature at which psychic disturbances begins in a child is a fair index of its brain stability. Neuropathic children. on a very slight rise in temperature or even without it, are subject to attacks of unreasonable elevation, during which they are quite beside themselves, rushing about wildly, shouting, fighting, and without clear consciousness of their surroundings. With this last picture stomatologists are very familiar in children brought to them for care of the teeth. During this period such disturbances have to be taken into account in cases where maxillary and dental treatment and regulation are indicated.

The period of puberty should include the period from the appearance of the menses or spermatozoa until the completion of the 25th year. The appearance of the wisdom tooth at this time marks human maturity, which was the reason that 25 was selected for the age of maturity by the code of Napoleon. During this period it is possible to correct dental and maxillary irregularities with benefit to the subject. Every one of the conditions enumerated are due to strain during the period between 6 and 12 may appear. In addition there occurs a type of mental disorder called hebephrenia, or insanity of puberty, which is practically incurable after its development. This is an insanity peculiarly charged to cigarette-smoking, masturbation, overstudy, religious excitement, and "love," all of which are the expressions of the defects and not their cause. These subjects in 
the carlier stage of their psychosis peculiarly require teeth regulation. In some cases, strain from the tooth irregularity may have sufficed to upset the unstable mental balance. The next great periods of stress in human life are those of the climacteric and of the senile period. 'The first is accompanied by the menopause in women and prostate change in men. The dental conditions marking these two periods of stress are generally involutional in character and require prothesis or treatment, not correction.

\section{DISCLSSION.}

DR. Eriugne S. TaLbot, Chicago-I have been interested in this subject for years and $I$ have spent a great many years in the study of these conditions. I have never heard a paper so clearly define those conditions as the one that has just been read. Someone has said that the discussion of dental subjects has been exhausted, but a knowledge of the conditions of the mouth so far as hereditary environment and embryology are concerned is still in its infancy. There are some points which deserve attention. Dentists often remark that if their patients were more careful with their teeth they would not decay, and then prescribe a course of treatment handed down for decades. The same old story is told of brushing the teeth, recommending the use of certain preparations, etc. As Dr. Kiernan said, evolution of the teeth is tending towards extinction. Decay of the teeth is a natural process and all the treatment on earth -as now applied-will not save them except in the individual. It is not only a personal calamity, but it has become a national one. Study of the teeth and jaws of the peoples of Europe shows teeth of men deteriorating. where the peoples are not of a nerrous tendency, as they are in other countries. Through Greece, Turkey, Russia, Norway, Sweden, France and England, in the order mentioned. is evident degeneracy of the jaws and teeth. There are no peoples in the world whose teeth are decaying to-day like those of the English people. There are no irregularities of the teeth like those of the English. In England it has become al national ealamity and the authorities have appointed committees and have furnished money to investigate the eause of decay of the teeth. All attention, the best methods of treatment will not save them.

Another question of the jaws and teeth that Dr. Kiernan has discussed, is the evolution of the second set of teeth. Dentists think they are able to treat pyorrhea alveolaris or gingivitis, and some claim to cure every case. Whth them it is simply a matter of local application, a peculiar sense of touch with instruments to remove all visible deposits. The condition is an atavistic one, and the disease is preventive to a certain extent. Still, should the individual live long enough, he would lose his teeth. This is a process of osteomalacia and nothing more than atavistic. As Dr. Kiernan has said, change of the teeth is going on continually. Where one tooth is shed in the lower vertebrates after it has done its duty, another takes its place. Where the temporary teeth are shed by absorption the second set takes its place. 'This absorption goes on with the second set and the teeth are lost in time. 'This occurs not in all cases, however, but in the majority, if the person lives long enough. Dr. Kiernan showed you a picture of the degeneracy and arrest of development. This is a picture where the child has grown to manhood, yet remained arrested in development. If the internal structures of the body were examined arrest of development would be evident. Ali have seen such cases, since they are very common. This particular condition illustrated, has arrest of development of the jaws and face. Dr. Kiernan remarks that structures that are temporary are changing from generation to generation.

For this reason dentists should be careful in regulating teeth, especially in children of from one to twelve years of age. These children are in the condition shown. In this neurotic condition the nervous system is very easily involved and also other organs of the hody. Children are often invalided for years by having their teeth regulated and dentists should be rery careful on that point. Another point about regulating teeth in such patients needs attention. Dentists can not tell int exact.y how it comes about, but where the teeth are moved by springs, ligatures and all kinds of appliances, they can not be held perfectly firm. Later in life absorption of the alveolar process occurs at this very point, due to osteomalacia or alveolar absorption. Later in life gingivitis sets in from regula. tion of the teeth, the jaws are never restored to health and the absorption goes on until the tepth become loose and are lost.

I want to call your attention to the picture. a four and onehalf months old embryo. All have seen children that have the appearance of age, with little hairs upon the face and ears, with wrinkles in the face, the hair frequently gray in spots, the skin drawn up and the fingers long and slender. In such patients, dentists should be very careful in the regulation of the teeth and in all operations. They always have irregularities and the greatest care is necessary because of the unbalanced nervous system.

Dr. VIDa A. Latham, Rogers Park, Hll.-It is a good thing to have the tension made elear on pathologic principles. Many teachers have made the statenient that it is absurd to suppose that the changes are made through the nerve functions. They can occur through tension, perhaps not permanently, but it is one of the factors underlying this development, or it may be through a case of retrogression. When we think of the enormous amount of force that goes on in the development of the teeth coming through four dental cycles, and of the congestion which involves the vasomotor and vasoconstrictor systems, we may come to the conclusion that it is due to the period of first stress. I have heard men advance the argument that pathologic stress is absurd; that it can not come from such a source, and was only a poor excuse for ignorance of some local condition.

Dr. G. V. I. Brown, Milwaukee-I can not say very much on this subject without encroaching on the paper that $I$ expect to read later on. I shall be obliged to disagree with Dr. Talbot concerning the regulation of teeth, because 1 have to begin to regulate the teeth of these young patients before they are entirely destroyed, and from all of which $I$ have demonstrated I can not agree with him. In regard to what he says of the disastrous results following the regulation of teeth in children and young persons, $I$ think it was rather the fault of the method than the age of the patient, and $I$ am convinced that where that continual absorption went on it was due to the effect of occlusion of the jaw's on account of malposition, which caused an irritation of the tissue around the mouth.

DR. JAMES G. Kiernan, Chicago-I only wish to correct a little terminology which $I$ think might be desirable in this Section. There is perhaps no word so misused and misleading as "degeneracy." The question is whether there is general degeneracy or whether it is a disappearance of certain parts for the benefit of the organism as a whole. It is true, a great many changes occur in this way for the benefit of the organism as a whole. The teeth are decreasing in number. There is very good reason to believe that man at one time possessed at least two extra incisors. There is also very good reason for believing that the wisdom tooth is tending to disappear. There is also good reason to believe that the human tooth is becoming microdont rather than macrodont, rather smaller than larger. This is along the general line of evolution with reference to the face and jaws. The human jaw itself with all its beauty, the human face, with all its beauty, is degenerate. For biting purposes and chewing purposes, it is not as valuable as the jowl of the lower races. It is an embryonic feature. It has lost space for the benefit of the brain. The brain has been absorbing more and more space at the expense of the bones of the face. Therefore, in dealing with this question of irregularities it would be wise to look at it in certain cases as a normal process. In certain cases it is wise to study the teeth not only from the point of regulation, but also from the standpoint of removal a little more than is done. No human hand can turn back the clock of time, retain a high type of man, and yet restore the jaw of a prehistoric ancestor who lived on food in which there was an enormous waste. The native or prehistoric races had beautiful teeth; but those teeth could not exist with the environment of the civilized races. 
Civilized man does not waste his tood so much; he does not need to do so much chewing and tearing. In the only animal that can be compared with man, the dog, similar changes are taking place, and these changes of domesticity are coincident with the changes occurring in civilized man. Another factor also infiuences these changes. There are many race types with different jaws and different teeth. No races are pure considered from this standpoint, but all races are intermixed. It is safe to say that every one of the English-speaking races has some primitive race element in them. Every one of the Teutonic races and every one of the Eur-African races have the same elements in them, and also the Eur-Asiatic. These races have different types of jaws, different sizes of teeth; from their mixture comes the so-called Aryan race. These people are subjected to a new environment. It is therefore a duty to study how far in one case removal of the teeth in a certain type might be a benefit in correcting irregularity, and how far in the other it might be injurious, and deal with the question from that standpoint. It can not be dealt with in a general way, but the individual conditions to which man is exposed must be studied. There is much nonsense talked about the degeneracy of the teeth. This is usually ascribed to luxury. 'The degeneracy is often an expression of the advance of the human race. When man gets fewer teeth, then there would not be so much irregularity, nor so much trouble in other directions.

\section{INFECTIOUS DISEASES.*}

\section{AlICE M. STEEVES, D.D.S.}

\author{
CHICAGO, ILL
}

i knowledge of the possibility of transferring infectious diseases from one patient to another by means if: instruments or otherwise, and of the character of the infection itself, is of the greatest practical value. While the necessity for proper precautions to avoid these accidents has long been recognized, the recent advances in the bacteriology of the mouth and throat cause the subject to assume new importance.

Of all diseases in which the infection is frequently (arried from the mouth of one patient to that of another, perhaps the most important is syphilis. In this affection two different lesions are formed in or about the mouth, each characteristic of the disease, and appearing at dif. ferent periods in its course. The primary sore is frequently to be found upon the lips or within the mouth. This is especially true in children. The mucous patche, of the secondary stage are usually seen in the moutk. where their seat is on the inner surface of the lip, tho tongue, the palate, or the fauces. In size they are from an eighth to half an inch in diameter, and while they extend superficially they are never deep. They aro whitish in color, with rounded edges and raised rather than depressed. These two lesions are the sources of most of the infection, which causes new cases of the disease, the virus being carried by actual contact, surgical instruments, household utensils or other accidental means; and to unaccustomed observers they may be overlooked or neglected, or considered harmless because their true character is not recognized.

The frequency with which these conditions occur and the great danger attached to them should warn every oral surgeon to be ready to recognize them and to take proper precautions to protect himself and others.

Modern research into the bacteriology of the mouth and throat has suggested new possibilities in the matter of carrving infection from patient to patient.

\section{The discovery that the germs of scarlet fever and diph}

* Read in the Section on Stomatology, at the Fifty-second Annual Meeting of the American Medical Association, held at St. Paul. Minn., June 4-7, 1901. theria may be found in perfectly healthy mouths and throats, and the fact that these germs remain in the mouth and throat for long periods after the clinical signs of the disease have disappeared, suggests the probability that these diseases may be transferred from patient to patient by unclean instruments. Well proven instances of this kind are indeed rare; yet this mode of infection is worthy of atcention.

The germs of diphtheria are sometimes found in tooth cavities or in a healthy throat, and although they may not cause the disease in that individual because of his natural resistance, when carried to the mucous membrane of a susceptible person they may produce the disease in a virulent form. The bacillus of diphtheria may be the cause of all grades of sore throat, from a simplo acute catarrh to an intense membranous inflammation extending into the nose and mouth; so that the true nature of a sore throat may not be recognized and the bacilli spread from patient to patient on septic instruments as is so often done by infected spoons and forks.

Diphtheria bacilli usually remain in the throat two weeks after the membrane has disappeared, but have been found five or six weeks afterwards in some cases. 'The infectious nature of purulent discharges following scarlet fever, such as a rhinitis or pharyngitis, are now fully recognized, so that, if after one of these infectious. diseases catarrhal inflammations are present, the necessary precautions can be taken to prevent new cases of the disease.

In the same manner, ervsipelas. which begins so often at the juncture of the skin and mucous membrane, and pus cocci from suppurating processes in the mouth may be transferred from patient to patient; and it is easily conceivable that the bacillus of tuberculosis could be taken from the mouth of a tuberculous patient on dental instruments and be deposited in the mouth of another patient and then find its way into the lungs.

\section{nIsCUSSION}

Dr. VIDA A. Latram, Rogurs Park, Ill.-This is a subject that is scarcely touched upon by dentists, but in connection with the physician we can accomplish a great deal in this direction. Many cities have a quarantine law, and in that way we can control these diseases in large cities, but it is more difficult where a physician is allowed to use his discretion in placarding a house. There is a great latitude in that method. If a physician is not perfectly honest and upright, he can probably l:e persuaded by higher fees or some other way to favor the family. A man will sell him that he has got to go to business, and the result is the physician does not quarantine the father of the family, and he goes to the bank or to his business without hindrance.

I have had two horrible cases of infection in little folks ihrough the non-disinfection of instruments. more especially torceps. In one case that was referred to a specialist, a - vphilitic lesion was calised in the upper jaw through the use (f) unclean instruments. In another case a woman contrar.t." primary syphilis and as I did not care to be in a malpractice suit, it was referred to a specialist. The cause was using infected forceps in extracting her teeth.

In dental schools how many students are trained to see ases of syphilis in the oral cavities? They do not see them because they are not pointed out. I have only seen them, because I have practiced medicine and dentistry. Few dental schools make any effort to classify or make a clinic for such diseases. Unquestionably, students ought to study and know these conditions. Most of us, if we should see a case, would not recognize it. Therefore, I hope the teaching of surgical cleanliness will be broader and deeper in all its branches.

Dr. Georae T. Carpenter. Chicago-The ordinary practitioner will not recognize the conditions, particularly syphilitic lesions, and it is a very diffirult matter. even where he suspects 